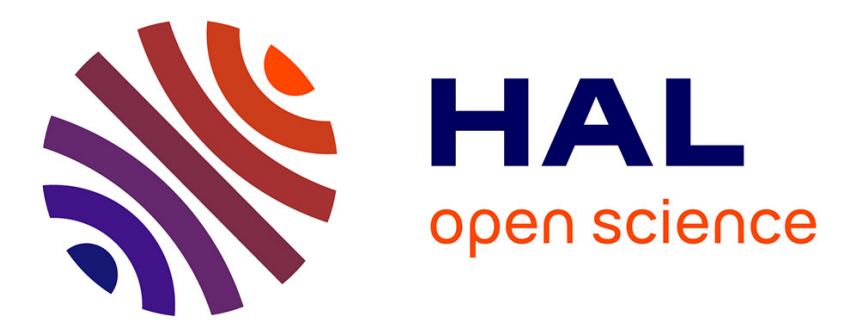

\title{
Ultra-wideband GCPW-MS-GCPW driven electrode for low-cost and wide range application electro-optic modulators
}

Mohammed El Gibari, Dominique Averty, Cyril Lupi, Hong Wu Li, Serge

Toutain

\section{To cite this version:}

Mohammed El Gibari, Dominique Averty, Cyril Lupi, Hong Wu Li, Serge Toutain. Ultra-wideband GCPW-MS-GCPW driven electrode for low-cost and wide range application electro-optic modulators. Microwave and Optical Technology Letters, 2010, 52 (5), pp.1078-1082. 10.1002/mop.25112 . hal00811636

\section{HAL Id: hal-00811636 \\ https://hal.science/hal-00811636}

Submitted on 23 Nov 2017

HAL is a multi-disciplinary open access archive for the deposit and dissemination of scientific research documents, whether they are published or not. The documents may come from teaching and research institutions in France or abroad, or from public or private research centers.
L'archive ouverte pluridisciplinaire HAL, est destinée au dépôt et à la diffusion de documents scientifiques de niveau recherche, publiés ou non, émanant des établissements d'enseignement et de recherche français ou étrangers, des laboratoires publics ou privés. 


\section{ULTRA-WIDEBAND GCPW-MS-GCPW DRIVEN ELECTRODE FOR LOW-COST AND WIDE RANGE APPLICATION ELECTRO-OPTIC MODULATORS}

\author{
Mohammed El-Gibari, Dominique Averty, Cyril Lupi, \\ Hongwu Li, and Serge Toutain \\ Faculté des Sciences et Techniques, Université de Nantes, Nantes \\ Atlantique Université, IREENA EA 1770, 2 rue de la Houssinière, \\ 44322 Nantes, France; Corresponding author: \\ mohammed.el-gibari@univ-nantes.fr
}

\begin{abstract}
Electro-optic modulators are key components in high bitrate optical transmissions. Decreasing the manufacturing cost without damage on performances is one of the most challenging issues for such components. We demonstrate that the electro-optic modulators based on polymer are compatible with high bandwidth requirements. Indeed, according to the results obtained by numerical simulation and partly validated by experiments, with the via-free GCPW-MS-GCPW electrodes proposed and analyzed in this article, the (400 $\mathrm{MHz}-67 \mathrm{GHz})$ bandwidth is achievable with electro-optic modulators based on suitable polymers. These encouraging results are very useful for low-cost mass production of polymer-based electro-optic modulators for a wide range of applications: digital and analogue high bit-rate transmissions.
\end{abstract}

Key words: electro-optic modulator; driven electrode; GCPW-MS transition; ultra-wide bandwidth component; polymers

\section{INTRODUCTION}

Optoelectronic components for fiber optic telecommunication require high performances. One of the main challenges is to reduce the manufacturing cost of components without decreasing their performances. Electro-optic modulators are such components that are concerned by this challenge: low driven voltage on broad electrical frequency bandwidth must be reached. Typically, a $6 \mathrm{~V}$ peak to peak driven voltage on the bandwidth (100 $\mathrm{kHz}-32 \mathrm{GHz}$ ) is required for $40 \mathrm{~Gb} / \mathrm{s} \mathrm{NRZ}$ transmission; the bandwidth can be reduced to $(100 \mathrm{kHz}-18 \mathrm{GHz})$ for $10 \mathrm{~Gb} / \mathrm{s}$ RZ transmission. Recent development in radio over fiber [1] provides new types of bandwidth specification: According to the IEEE 802.16 family of standards for wireless metropolitan area, 25-28 MHz channels are required in the (10-66 GHz) band. The use of polymer material to realize such optoelectronic devices is proposed in the literature [2]. Usually, electro-optic polymer is deposited into thin films by spin coating (typically $10-\mu \mathrm{m}$ thickness); electrical driving signal is applied to the optical waveguide in polymer with a microstrip waveguide (MS) to optimize the efficiency of the electro-optic interaction (Fig. 1). To characterize such components, it is convenient to use a coplanar waveguide (CPW) probe station, so a CPW-to-MS transition is required. Characterization could also be done with connector, but because of the low thickness of the substrate, the use of a coax-to-CPW connector is better than the use of a coax-toMS one. Moreover, the output port of the transmission line must be connected on a $50-\Omega$ load; this can be done directly on a CPW electrode by reporting a $50-\Omega$ chip between the electrode and the ground plane. In other words, the optimization of a CPW-MS-CPW line is essential to characterize and realize electro-optic modulators on thin films polymer. Several structures have been proposed in the literature [3-7]. In our study, we focused on vialess transition to avoid additional fabrication step so as to keep the manufacturing cost as low as possible. Zhu and Melde [7] proposed to optimize the electromagnetic coupling between the ground planes of the CPW (in this case only two pads) line and the ground plane of the MS line to increase the bandwidth. At first we compare the different vialess structures proposed in the literature [4-7] on a standard substrate PTFE/glass/ceramic NH9338. According to our application, we analyze the evolution of the simplest structure (which requires the minimum fabrication steps) versus the substrate thickness: simulations and measurements are compared and discussed. Then, some transition structures on SU8 polymer thin film (optical polymer cladding of $8-\mu \mathrm{m}$ thickness) are realized. The results obtained demonstrate that it is possible to realize a basic CPW-MS-CPW line compatible with low-cost electro-optic polymer-based modulators that can be used for the different bandwidths required. Then, we discuss about the effect of the metallization thickness and the loss tangent of the optical polymer cladding on the bandwidth.

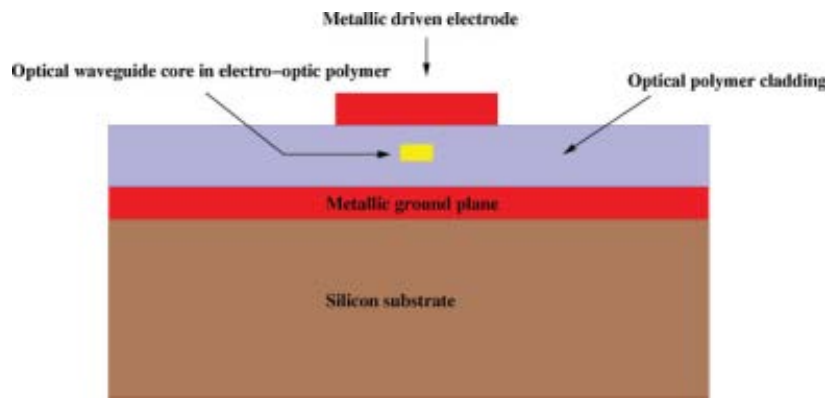

Figure 1 Cross section of an electro-optic polymer-based modulator. [Color figure can be viewed in the online issue, which is available at www.interscience.wiley.com] 


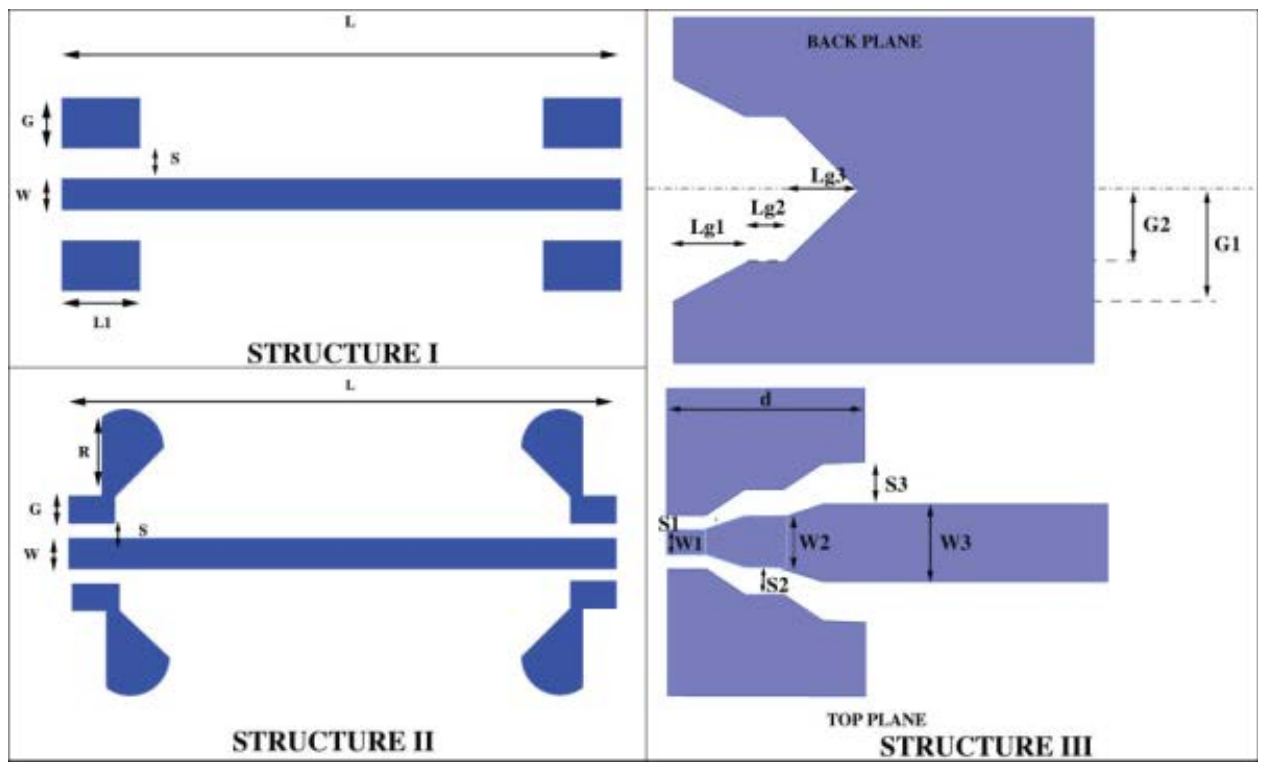

Figure 2 Back-to-back CPW to MS transition structures. [Color figure can be viewed in the online issue, which is available at www.interscience.wiley.com]

\section{GCPW-MS-GCPW DRIVEN ELECTRODE ANALYSIS}

Several structures have been proposed in the literature to realize a vialess CPW-MS transitions. We essentially focus our attention on the proposition made by Strauss et al. [4] and Zhu and Melde [7].

The structures II and III, shown in Figure 2, respectively, proposed by Strauss et al. and Zhu and Melde give promising bandwidths. To compare their performances, we choose to reproduce them on a (1/40)" thick NH9338 substrate (loss tangent $\tan \delta=0.0047$ and a permittivity equal to 3.41 ). We also choose to realize the simplest structure referenced as structure I in Figure 2, because it offers the best low cutoff frequency. Unlike the structure III, the structures I and II are GCPW-MSGCPW transitions (GCPW as grounded CPW). The dimensions of structures have been determined to have a $50-\Omega$ characteristic impedance in each of their sections (cf. Table 1).

Electromagnetic simulation of the three different CPW-MSCPW structures has been carried out with the HFSS software. The S21-parameter of each structure is presented in Figure 3(a). To obtain a good agreement between measurements and simulations, the excitation must be modeled exactly as the probe is used for the characterization. In HFSS software, we used the lumped port with the exact parameters of our coplanar probe. The widest bandwidth is obtained with the structure proposed

TABLE 1 Dimension Parameters of the Simulated and Realized Transition Structures in Figure 2

\begin{tabular}{lcc}
\hline Structure I & Structure II & Structure III \\
\hline$L=2 \mathrm{~cm}$ & $L=2 \mathrm{~cm}$ & $W_{1}=1 \mathrm{~mm}$ \\
$L_{1}=2 \mathrm{~mm}$ & $R=1.5 \mathrm{~mm}$ & $W_{2}=1.2 \mathrm{~mm}$ \\
$S=150 \mu \mathrm{m}$ & $S=150 \mu \mathrm{m}$ & $W_{3}=1.4 \mathrm{~mm}$ \\
$W=1.4 \mathrm{~mm}$ & $W=1.4 \mathrm{~mm}$ & $S_{1}=125 \mu \mathrm{m}$ \\
$G=2 \mathrm{~mm}$ & $G=0.5 \mathrm{~mm}$ & $S_{2}=140 \mu \mathrm{m}$ \\
& Stub angle $=30^{\circ}$ & $S_{3}=1 \mathrm{~mm}$ \\
& & $L=2 \mathrm{~cm}$ \\
& & $d=2 \mathrm{~mm}$ \\
& & $L_{\mathrm{g} 1}=L_{\mathrm{g} 2}=L_{\mathrm{g} 3}=0.75 \mathrm{~mm}$ \\
& $G_{1}=1.5 \mathrm{~mm}$ and $G_{2}=0.5 \mathrm{~mm}$ \\
\hline
\end{tabular}

by Zhu and Melde, but it requires etching the background plane, so an additional fabrication step is necessary with careful alignment of the patterns on both sides of the substrate. In the transition I, propagating mode is a quasi-TEM mode. However, as presented in Figure 4, the field chart varies to satisfy the continuity relations. As Raskin et al. proposed in [8], we will call these three configurations CPM (coplanar microstrip) mode, MS mode, and CPW mode.

From this analysis, we choose to decrease the thickness of the substrate for the structure I to promote quickly the conversion from CPW mode to MS mode and to minimize the excitation of CPM mode. Then, we study the evolution of the S21-parameter for the structure I realized on NH9338 substrate for three standard substrate thicknesses [Fig. 3(b)]. The structure dimensions have been modified to keep the characteristic impedance of the line at $50 \Omega$. From the results presented in Figure 3, we observed a significant increase of the bandwidth up to 36 $\mathrm{GHz}$ by decreasing the thickness of the substrate to the value of $127 \mu \mathrm{m}$. The bandwidth of the structure I is limited in high frequency by the CPW length $\left(L_{1}\right)$ in the transition because of the CPM mode between the back ground plane and the ground track. Shorter this length is, higher the high cutoff frequency is. To check our simulations results, the structure I has been realized with two different lengths $L_{1}, 5 \mathrm{~mm}$ for Figures 3(c) and 3(d) and $1 \mathrm{~mm}$ for Figures 3(e) and 3(f). The $S$-parameters of the transition lines have been measured with a CPW probe station. The simulated and experimental results are in good agreement. The transition with larger length $L_{1}$ [cf. Figs. 3(c) and $3(d)]$ provides a lower high cutoff frequency: the quarter wavelength effect is observed at $15 \mathrm{GHz}$, the decrease of the length $L_{1}$ rejects this effect to higher frequency [cf. Figs. 3(e) and $3(\mathrm{f})$ ], resulting in an extension of the bandwidth to $30 \mathrm{GHz}$ because of the excitation of CPM mode in the structure. For the transition line presented in Figures 3(c) and 3(d), a $-3 \mathrm{~dB}$ bandwidth can be obtained from 8 to $30 \mathrm{GHz}$ with a value of return loss lower than $-10 \mathrm{~dB}$. From these results, the simple structure I exposed by Strauss et al. [4] could be applied to very thin film substrate to provide the required bandwidth for low-cost polymer electro-optic modulators. 

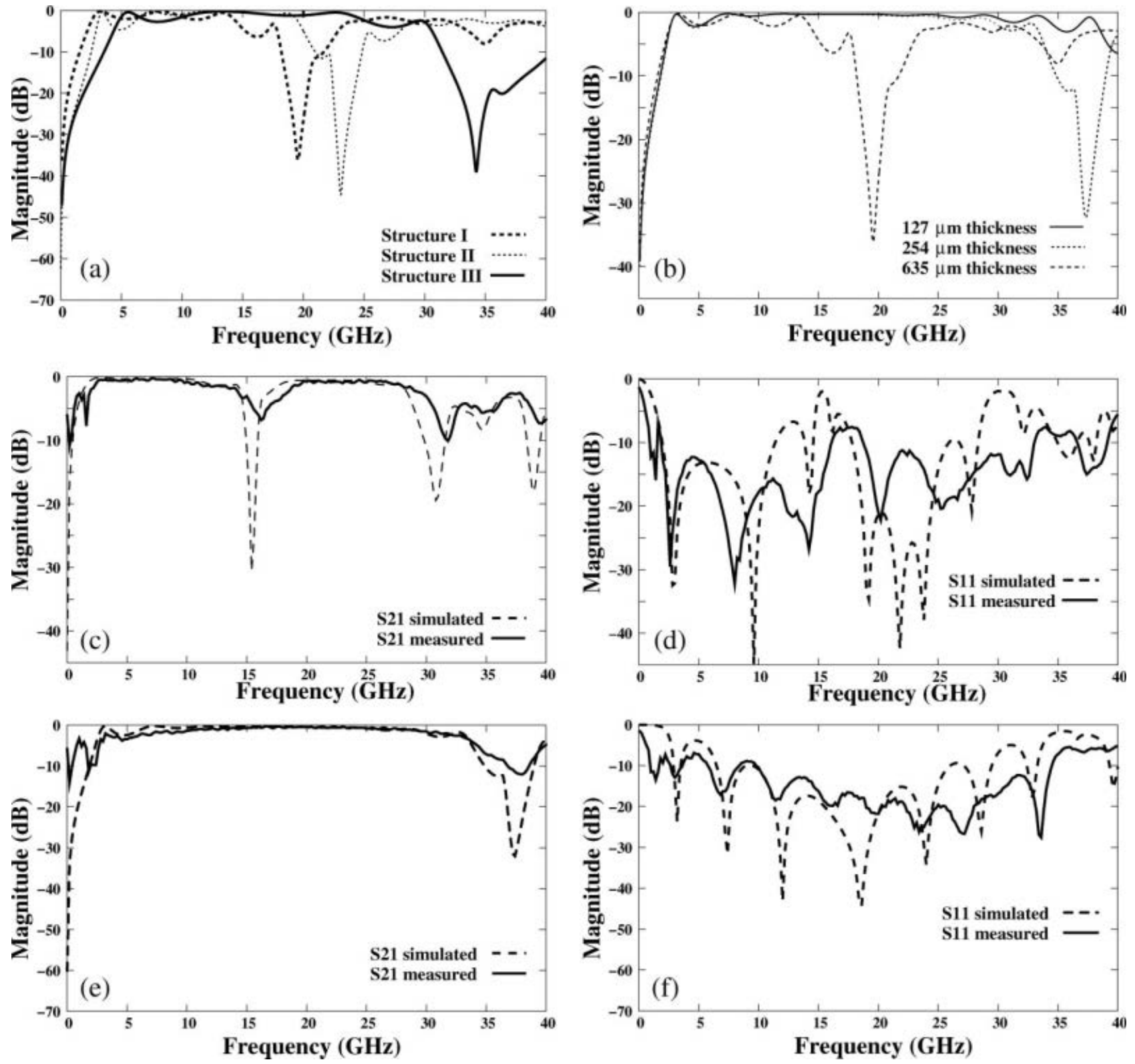

Figure 3 Study of $S$-parameters of the transitions shown in Figure 2: (a) S21-parameter simulation of the different structures, (b) S21-parameter simulation of the structure I for different substrate thicknesses, (c) measured and simulated $S 21$-parameter for the structure I with $L_{1}=5 \mathrm{~mm}$, (d) measured and simulated $S 11$-parameter for the structure I with $L_{1}=5 \mathrm{~mm}$, (e) measured and simulated $S 21$-parameter for the structure I with $L_{1}=1 \mathrm{~mm}$, and (f) measured and simulated $S 1$-parameter for the structure I with $L_{1}=1 \mathrm{~mm}$

\section{APPLICATION TO THIN FILM POLYMERS}

According to the results presented earlier, we propose to study the bandwidth obtained with the simple structure I with a $8-\mu \mathrm{m}-$ thick optical polymer cladding utilized as microwave transition substrate. This structure is suitable for the realization of a lowcost modulator because polymer materials are low cost and can be deposited into thin film by spin coating, no via in the substrate nor etching of the ground plane is necessary for making GCPW-MS-GCPW transitions. So, a 8 - $\mu$ m-thick SU8 polymer $\left(\tan \delta=0.043, \varepsilon_{\mathrm{r}}=3.55\right)$ thin film is first deposited on a metallized silicon wafer, then the structure I with a $370-$ nm-thick aluminum metallization thickness and $L_{1}=1 \mathrm{~mm}$ is realized on this SU8 substrate. Made with a high electro-optic coefficient polymer material [2], electro-optic modulators can operate with an acceptable half-wave voltage of about $5 \mathrm{~V}$ and a $1 \mathrm{~cm}$ interaction length, that is why in this section, we analyze $1-\mathrm{cm}$ long
GCPW-MS-GCPW driven electrode on polymer. The measured and simulated results in good agreement are presented in Figure 5(a). Large losses make unusable this structure for the realization of a competitive electro-optic modulator. The low metallization thickness is mainly responsible for the losses observed in the transitions under test. Simulations with different aluminum metallization thicknesses (SU8 substrate and $L_{1}=2 \mathrm{~mm}$ ) are presented in Figure 5(b); the results show that the transition with a $6-\mu \mathrm{m}$-thick aluminum metallization gives a $(210 \mathrm{MHz}-$ $30.75 \mathrm{GHz}$ ) bandwidth. By this way, the bandwidth features of the GCPW-MS-GCPW line are closed to those required for various applications of electro-optic modulators, radio over fiber particularly. Then, a simple analysis shows that to decrease the low cutoff frequency we can enlarge the area of the CPW ground pads by increasing either the ground pads' length $L_{1}$ or their width $G$. But, as shown previously, that results in decrease 


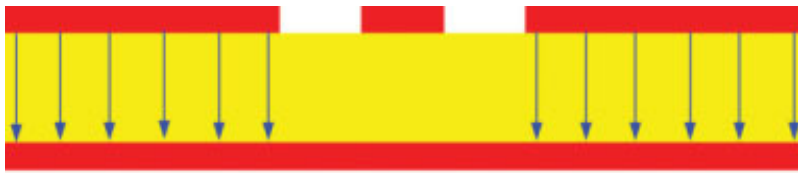

CPM mode

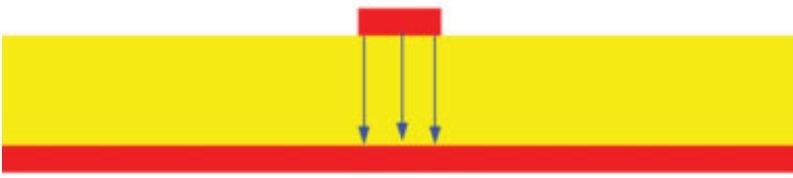

MS mode

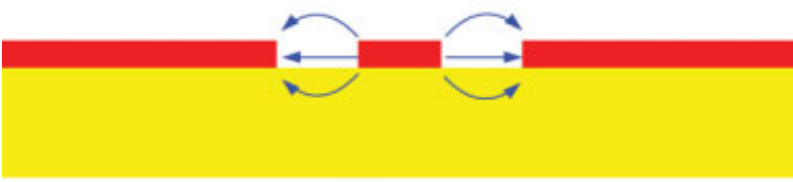

CPW mode

Figure 4 Electrical field distribution in the transition structure I. [Color figure can be viewed in the online issue, which is available at www.interscience.wiley.com]

in the high cutoff frequency, so a trade-off must be found. To increase the high cutoff frequency, some metal with higher conductivity than the aluminum can be used; as an example, we compare in Figure 5(c) the bandwidths of the transitions with three standard metals on SU8 polymer thin film for $L_{1}=1 \mathrm{~mm}$. In this simulation, the use of silver or copper metallization allows to extend the $-3 \mathrm{~dB}$ high cutoff frequency to $30 \mathrm{GHz}$. One of the parameters responsible for the limited bandwidth is the dielectric losses of the optical polymer cladding $(\tan \delta$ value) in which the wave is propagating. For our experimental study, we used a SU8 resin that resists well to chemical etching but has a large loss tangent; some other optical polymer claddings are commercially available with lower $\tan \delta$ value. For example, the NOA polymer has a permittivity equal to 3.22 with $\tan \delta=0.013$ (more than three times lower than that of SU8).

Figure 5(d) gives the S21-parameter for two standard commercial polymers, which can be used as optical cladding (tan $\delta(\mathrm{NOA})=0.013, \tan \delta(\mathrm{SU} 8)=0.043)$. To draw some synthetic conclusions and trends from our results, we put together in Table 2 the bandwidths computed with HFSS for different thicknesses and types of metallization for two lengths $L_{1}$ of the structure I. According to the results in Table 2, it is possible to achieve a $(420 \mathrm{MHz}-60.35 \mathrm{GHz})$ bandwidth with appropriate optical claddings from the point of view of microwave loss, $L_{1}=1 \mathrm{~mm}$, the structure I and a $6-\mu \mathrm{m}$-thick silver metallization. To reach the widest application range components for radio over fiber communication, it will be very interesting to synthesize optical polymer claddings with electrical losses equal to those of $\mathrm{NH} 9338(\tan \delta(\mathrm{NH} 9338)=0.0047)$. In this case, a (420 MHz-67.39 GHz) bandwidth would be achievable [Fig. 5(d) and Table 2].
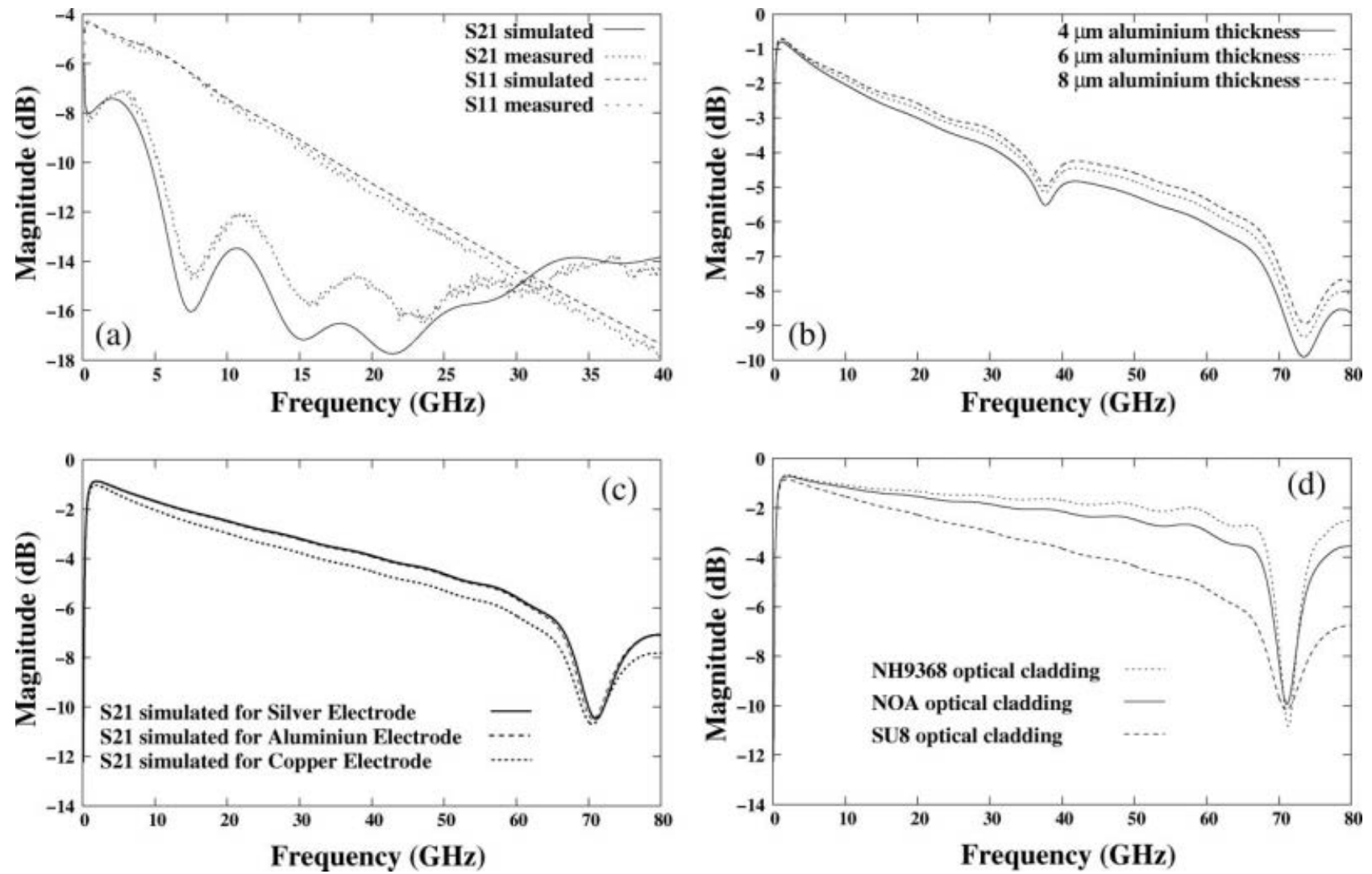

Figure 5 Numerical and experimental studies of $S$-parameters for different parameters of polymer-based electro-optic modulators with the GCPW-MSGCPW transition structure I: (a) $S$-parameters measured and simulated for SU8 optical cladding with 370-nm-thick aluminum metallization and $L_{1}=$ $1 \mathrm{~mm}$, (b) $S 21$-parameters simulated for different thicknesses of aluminum metallization (SU8 and $L_{1}=2 \mathrm{~mm}$ ), (c) $S 21$-parameters simulated for different electrode metals (SU8 and $L_{1}=1 \mathrm{~mm}$ ), and (d) $S 21$-parameters for different optical cladding materials (aluminum metallization and $L_{1}=1 \mathrm{~mm}$ ) 
TABLE $2-3 \mathrm{~dB}$ Bandwidth of the Transition Structure I with Different Parameters, Optical Claddings, and Metallization

\begin{tabular}{lcccc}
\hline $\begin{array}{l}\text { Optical } \\
\text { Cladding }\end{array}$ & Metal & $\begin{array}{c}L_{1} \\
(\mathrm{~mm})\end{array}$ & $\begin{array}{c}\text { Metal } \\
\text { Thickness } \\
(\mu \mathrm{m})\end{array}$ & Bandwidth \\
\hline SU8 & $\mathrm{Al}$ & 1 & 4 & $420 \mathrm{MHz}-20.45 \mathrm{GHz}$ \\
SU8 & $\mathrm{Cu}$ & 1 & 4 & $420 \mathrm{MHz}-26.7 \mathrm{GHz}$ \\
SU8 & $\mathrm{Ag}$ & 1 & 4 & $420 \mathrm{MHz}-27.6 \mathrm{GHz}$ \\
SU8 & $\mathrm{Ag}$ & 1 & 6 & $420 \mathrm{MHz}-30.75 \mathrm{GHz}$ \\
SU8 & $\mathrm{Ag}$ & 1 & 8 & $420 \mathrm{MHz}-31.8 \mathrm{GHz}$ \\
SU8 & $\mathrm{Ag}$ & 2 & 8 & $210 \mathrm{MHz}-31.56 \mathrm{GHz}$ \\
NOA & $\mathrm{Ag}$ & 1 & 6 & $420 \mathrm{MHz}-60.35 \mathrm{GHz}$ \\
NOA & $\mathrm{Ag}$ & 2 & 6 & $210 \mathrm{MHz}-36.71 \mathrm{GHz}$ \\
NH9338 & $\mathrm{Ag}$ & 1 & 6 & $420 \mathrm{MHz}-67.39 \mathrm{GHz}$ \\
\hline
\end{tabular}

\section{CONCLUSIONS}

We demonstrate that it is possible to realize an ultra-wide band driven electrode without etching the ground plane and without via-holes in the optical claddings. The driven electrode is an important element in electro-optic modulators; particular attention should be paid to the optimization of its design to improve the overall performance of the modulators, especially the bandwidth and the half-wave voltage $V \pi$. In the case of polymer-based electro-optic modulators, the interest of our study of the microwave transition is double. On the one hand, the thinness of polymer films used in these modulators makes the GCPW-MSGCPW transition proposed and analyzed in this article, particularly suitable to them. On the other hand, the polymer-based electro-optic modulators have an enormous potential bandwidth thanks to a good optical-microwave phase match in polymers over $100 \mathrm{GHz}$, while that of their counterparts made of $\mathrm{LiNbO}_{3}$ is limited to about $40 \mathrm{GHz}$. They need absolutely an electrode with a very wide bandwidth. The results presented in this article are very promising for realizing ultra-wide band and low-cost electro-optic modulators based on polymer. The bandwidth (420 $\mathrm{MHz}-67.39 \mathrm{GHz}$ ) allows polymer-based electro-optic modulators to be used in a wide range of applications, such as digital and analogue optical transmission, wireless transmission in radio over fiber systems.

\section{ACKNOWLEDGMENTS}

The authors thank Dr. Nicolas Barreau with Institut de Matériaux de Nantes for his help in realizing metallization operation, M. Marc Brunet and Dr. Yann Mahé with IREENA for their help in microwave characterization with probe station and in using HFSS software, respectively, the Region of Pays de la Loire and the ANR (French National Research Agency) for their support through the project Mattador/MILES and the project ModPol, respectively.

\section{REFERENCES}

1. M. Garcia Larrode, A.M.J. Koonen, and J.J. Vegas Olmos, Overcoming modal bandwidth limitation in radio-over-multimode fiber links, IEEE Photo Technol Lett 18 (2006), 2428-2430.

2. R.J. Michalak, Y.-H. Kuo, F.D. Nash, A. Szep, J.R. Caffey, P.M. Payson, F. Haas, B.F. Mckeon, P.R. Cook, G.A. Brost, J. Luo, A.K. Jen, L.R. Dalton, and W.H. Steier, High speed AJL8/APC polymer modulator, IEEE Photo Technol Lett 18 (2006), $1207-1209$.

3. M. Houdart and C. Aury, Various excitations of coplanar waveguide, IEEE MTT-S Int Microwave Symp Dig 79 (1979), 116-118.
4. G. Strauss, P. Ehret, and W. Menzel, On-wafer measurement of microstrip-based MIMICs without via holes, IEEE MTT-S Int Microwave Symp Dig 3 (1996), 1399-1402.

5. A.M.E. Safwat, K.A. Zaki, W. Johnson, and C.H. Lee, Novel transition between different configurations of planar transmission lines, IEEE Microwave Wireless Compon Lett 12 (2002), 128-130.

6. Y. Wang and M.J. Lancaster, Coplanar to microstrip transitions for on-wafer measurements, Microwave Opt Technol Lett 49 (2007), 100-103.

7. L. Zhu and K. Melde, On-wafer measurement of microstrip-based circuits with a broadband vialess transition, IEEE Trans Adv Packaging 29 (2006), 654-659.

8. J.-P. Raskin, G. Gauthier, L.P. Kathei, and G.M. Rebeiz, Mode conversion at GCPW-to-microstrip-line transitions, IEEE Trans Microwave Theory Tech 48 (2000), 158-161. 